\title{
LEVANTAMENTO E ANÁLISE MORFOMÉTRICA DA BACIA HIDROGRÁFICA DO RIO CABAÇAL-MT
}

\author{
Evandro André Félix ${ }^{(a)}$, Célia Alves de Souza ${ }^{(b)}$ \\ (a) PPGGEO, Universidade do Estado de Mato Grosso-UNEMAT, eafeliks@ gmail.com \\ (b) PPGGEO, Universidade do Estado de Mato Grosso-UNEMAT, celiaalvesgeo@globo.com
}

\section{EIXO: BACIAS HIDROGRÁFICAS E RECURSOS HÍDRICOS: ANÁLISE, PLANEJAMENTO E GESTÃO}

\begin{abstract}
Resumo
O levantamento e análise morfométrica se consolidaram como ferramentas essências ao estudo aplicado a bacias hidrográficas por permitir diagnósticos lineares e areal de forma rápida e precisa. Dentro deste contexto, o objetivo deste trabalho foi realizar o levantamento e análise morfométrica da bacia hidrográfica do rio Cabaçal, localizada a sudoeste de Mato Grosso, utilizando Modelo de Elevação digital da área e as formulas de obtenção dos parâmetros morfométricos. Com 5.762,08 km² de área a bacia é drenada por um canal principal de $231,86 \mathrm{Km}$ que até a foz com o rio Paraguai concentra um total de $12.744,38 \mathrm{Km}$ de canais, ordenados até $8^{\circ}$ ordem. Os parâmetros de compacidade $(3,39)$, circularidade $(0,008)$, razão do relevo $(0,003)$, densidade dos rios de $(5,8)$ e densidade da drenagem de $2,2 \mathrm{~km}$, evidenciam uma rede de drenagem disseca e estruturada no relevo, com baixa susceptibilidade inundação em virtude da alta capacidade de drenagem.
\end{abstract}

Palavras chave: Morfometria, Bacia Hidrografica, Rio Cabaçal

\section{Introdução}

Consagradas como instrumento estratégico de planejamento regional as bacias hidrográficas compreendem um conjunto de terras drenadas por um rio principal e seus afluentes, dispostos hierarquicamente. Assim, a bacia é composta por divisores topográficos, cabeceiras e/ou nascentes de onde a água escoa dos pontos mais altos para os mais baixos, conferindo-lhe dinamismo sistêmico, promovido pelas modificações que ocorrem nas linhas divisoras e em toda a rede de drenagem em decorrência da atuação dos agentes e processos erosivos (naturais e ou antrópicos) (GUERRA e GUERRA, 2003, p. 76).

De acordo com Christofoletti (1980, p. 106), "o engenheiro hidráulico Robert E. Horton precursores nos estudos relacionados ao desenvolvimento dos rios e bacias hidrográficas, visualizando o conjunto de canais sob a ótica quantitativa, permitindo novas possibilidades metodológicas de análise", ressalta ainda que tais contribuições foram influenciadas pelos estudos de classificação e hierarquização de Artur N. Stralher. 
Para Machado e Lobão, et al (2011, p. 1141) a análise morfométrica "objetiva estabelecer as relações entre os parâmetros mensuráveis de uma bacia hidrográfica e os seus condicionantes". Salles (2010, p. 5) afirma que esta técnica pode ser "entendida como uma análise quantitativa dos elementos resultantes do modelado do relevo (expressão e configuração espacial), sendo o conjunto das vertentes e canais que compõem o relevo".

Freire, Lage e Christófaro (2013, p. 5445) destacam que "os parâmetros morfométricos, são obtidos mediante cálculos das variáveis, forma, relevo e drenagem", considerando, portanto, os padrões fisiográficos da paisagem sobre a ótica da mensuração traduzidos em modelos numéricos que permitam a compreensão da dinâmica do relevo e da rede de drenagem que interage com a paisagem.

Por sua vez, Neto (2008) afirma que as análises morfométricas passaram a ter papel significativo nos estudos sistêmico em geografia por meio da escola anglo-americana com Horton, Strahler, Hack. Assim, a análise morfométrica e areal de bacias hidrográficas e canais fluviais ganham impulso, tendo em vista que a proposição sistêmica associa à análise quantitativa e o uso de modelos. Estas características e a possibilidade de um diagnóstico rápido e qualificado, associado à geotecnologias a morfometria tem sido amplamente utilizada nos estudos de bacias hidrográficas com trabalhos de referência desenvolvidos em todas as regiões brasileiras, dentre as quais podemos destacar: Morfometria bacia hidrográfica do Carão, Estado do Ceará (FRANÇA, OLIVEIRA et al 2014), Análise morfométrica das sub-bacias hidrográficas Perdizes e Fojo no município de Campos do Jordão São Pulo (SANTOS, TARGA, et al., 2012). A análise da morfometria de bacias hidrográficas sujeitas a inundações na região Sul de Santa Catarina (SEHNEM, RODRIGUES, et al 2015), caracterização morfométrica e capacidade de uso da terra da bacia hidrográfica do rio Sararé, Sudoeste do estado de Mato Grosso (PINTO, 2015) e a caracterização morfométrica de subbacias hidrográficas na calha do rio Solimões/Amazonas (SOUSA, ARRAES, et al 2016), dentre outros.

Dentro deste contexto, o objetivo do trabalho foi realizar levantamento e análise morfométrica da bacia hidrográfica do rio Cabaçal, afluente da margem direita do rio Paraguai no estado de Mato Grosso.

\section{Materiais e métodos}

\section{1 Área de Estudo.}

A bacia hidrográfica do rio Cabaçal, abrange uma área de 5.762,08 km² e compõe a drenagem da bacia do Alto Paraguai (BAP), localiza-se entre as coordenadas geográficas de $15^{\circ} 0$ '0' $\mathrm{S}$ a $16^{\circ} 0$ '0" de

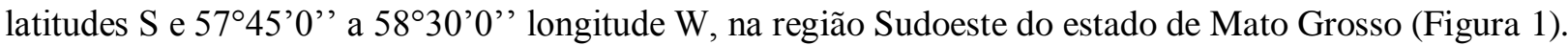




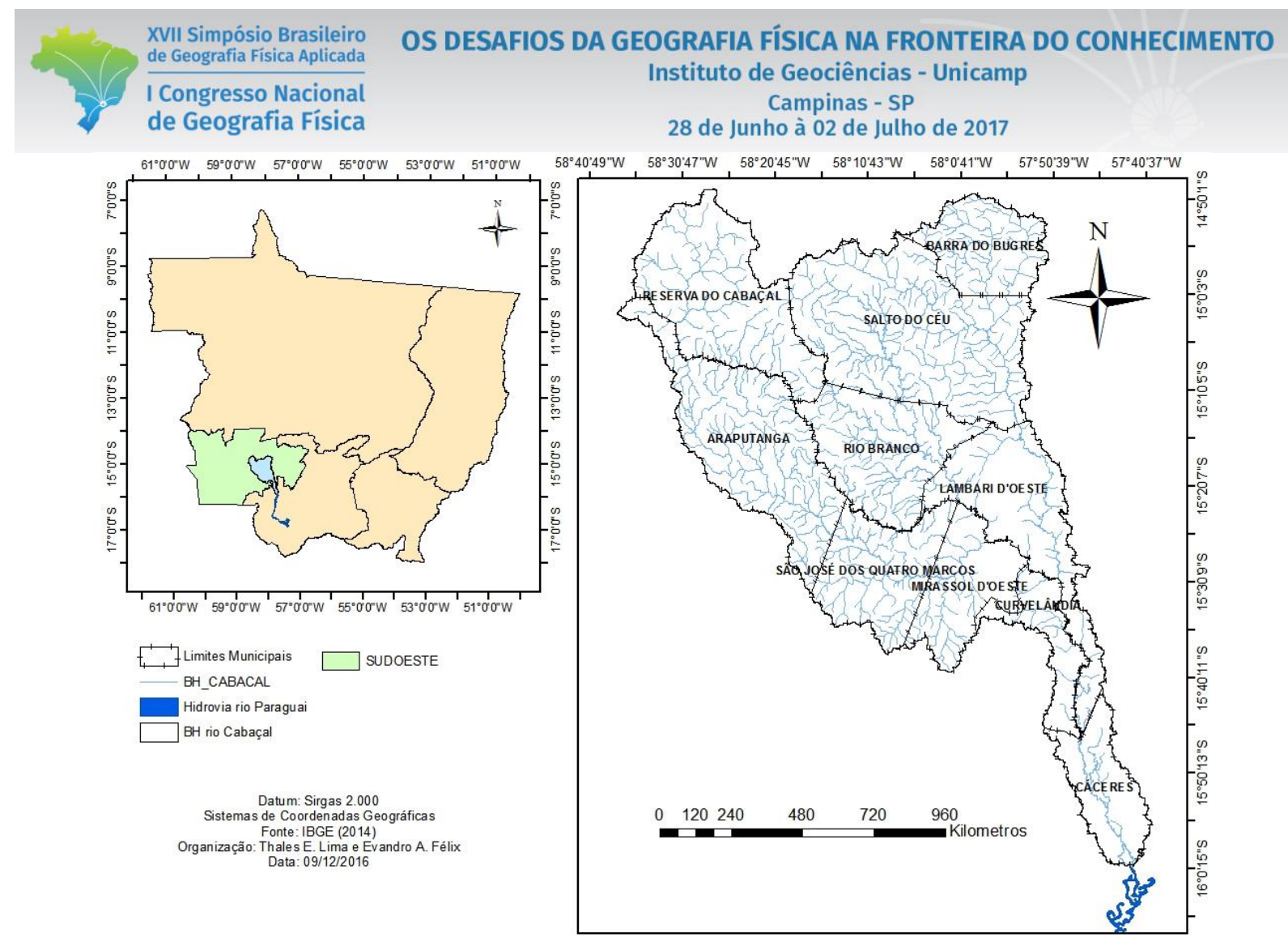

Figura 1- Localização da Bacia Hidrográfica do Rio Cabaçal

\subsection{Procedimentos metodológicos.}

As informações foram geradas a partir de imagens do Modelo Digital de Elevação (MDE), projeto Topodata http://www.webmapit.com.br/inpe/topodata/. O banco de dados em formato raster foi processado no software ArcGis 10.1 e Qgis 2.18 Las Palmas.

Foram projetadas cinco imagens do MDE para o datum Sirgas 2000 no software ArcGis. Em seguida, foram utilizadas as ferramentas "Extract by mask", "Mosaic to raster", selecionar e unir as imagens para extração dos dados de declividade, rede de drenagem e altimétricos. A ferramenta "Calculate Geometry" "Symbology" e "Hillshade effect” foi utilizada para quantificar a área e o perímetro.

Para o mapa de declividade, as imagens do MDE foram convertidas para o datum UTM Sirgas 2000 - Zona 21 S, no software Qgis 2.18, em seguida, foram processadas na ferramenta "Análise do Raster", no modo declividade em (\%).

Os intervalos de declividade foram estabelecidos conforme Embrapa (1979), de modo que as classes foram apresentadas em: $0 \%-2 \%$ (plano), $2,1 \%-5 \%$ (suave ondulado), $5,1 \%-10 \%$ (ondulado), 
$10,1 \%$ - 15\% (moderadamente ondulado), 15,1\% - 45\% (forte ondulado), 45,1\% - 70\% (montanhoso) e acima de 70,1\% como escarpado. O ordenamento da drenagem foi processado utilizada a ferramenta "Spatial Analyst Tools" do ArcGis. ("Fill”, "Flow Acumulation”, "Flow Direction", "Stream", "Stream Order" e "Stream to Feature").

\subsection{Obtenção dos dados morfométricos}

Os dados morfométricos foram obtidos observando os critérios de Smith (1950) Horton (1945) e Strahler (1957) apud Christofoletti (1980).

Índice de compacidade $\left(K_{C}\right)$. De acordo com Garcez e Alvarez (1998), é a relação do perímetro da bacia e um círculo de igual área, quando o $K_{C}$ se aproxima de um, a bacia tende ao formato circular, indicando maior propensão a cheias. Fórmula: onde P - Perímetro e $A_{k m^{2}}$ - Área da bacia em quilômetros quadrados.

$$
K_{C}=0,28 x \frac{P}{\sqrt{A_{k m^{2}}}}
$$

Índice de circularidade $\left(K_{e}\right)$. Conforme Miller (1953) apud Christofoletti (1980), o índice de circularidade indica suscetibilidade às cheias ao se aproximar de 1 . $\mathrm{O}$ parâmetro foi calculado pela equação:

$$
K_{e}=\frac{12,57 \times A}{P^{2}}
$$

Fator de forma $\left({ }^{k_{f}}\right)$ Fator de forma é a relação entre a largura média e o comprimento axial da bacia. A largura média $\left(L_{m}\right)$ obtém-se dividindo a área (A) pelo comprimento da bacia (L). (COSTA e LANÇA, 2011, p. 9). Sendo: ${ }^{L_{m}}$ - m ou km, L - m ou km A - m ou km sendo $k_{f}$ - adimensional.

$$
L_{m}=\mathrm{A} / \mathrm{L} \quad k_{f}=\frac{A}{L^{2}} \quad \text { ou } \quad k_{f}=\frac{L_{m}}{L}
$$

Altitude média $\left(\boldsymbol{H}_{\boldsymbol{m}}\right)$ De acordo com Castro e Lopes (2001) a $H_{m}$ da bacia influencia a evapotranspiração, temperatura e precipitação. A média aritmética foi obtida observando os valores de maior e menor altitude. Observando que: $A M^{x}=$ maior altitude em metros; $A M^{m}=$ menor altitude em metros.

$$
H_{m}=\frac{A M^{x}+A M^{m}}{2}
$$


Amplitude altimétrica $(\mathrm{H})$. A amplitude altimétrica é a diferença entre a maior e a menor altitude da bacia e é expressa em metros (CHRISTOFOLETTI, 1980), foi obtida pela expressão:

$$
H=A M^{x}-A M^{m}
$$

Declividade média $\left(\boldsymbol{D}_{m}\right)$. A declividade média apresenta relação com os processos hidrológicos, como o escoamento superficial, infiltração e tempo de concentração da água nos canais de drenagem (TONELLO et al., 2006). Sendo $(C)$ o maior comprimento do canal principal e $(P)$ o perímetro da bacia

$$
D_{m \%}=\frac{C}{P}
$$

Razão de relevo $\left(\boldsymbol{R}_{\boldsymbol{r}}\right)$. Razão de relevo $\left(\boldsymbol{R}_{\boldsymbol{r}}\right)$, foi obtida conforme Schumm (1956), e está relacionado a amplitude altimétrica máxima e a maior extensão da bacia. Observando que $H_{m x}=$ Altitude máxima ; $L_{h}=$ Maior comprimento da bacia em metros.

$$
R_{r}=\frac{H_{m x}}{L_{h}}
$$

Densidade de rios $\left(\boldsymbol{D}_{\boldsymbol{r}}\right)$. Esse parâmetro, proposto por Horton (1945), estabelece a relação entre o número de cursos d'água e a área de uma dada bacia. Considerando que: $D_{r}=$ Densidade de rios e o $N^{T \cdot c}$ = Números total de canais e $A_{B h}=$ Área da bacia.

$$
D_{r}=\frac{N^{T \cdot c}}{A_{B h}}
$$

De drenagem $\left(\boldsymbol{D}_{d) \text { : }}\right.$ Densidade de drenagem correlaciona o comprimento total dos canais de

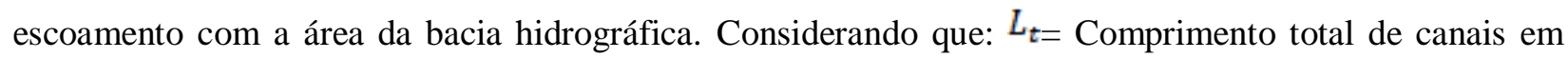
$\mathrm{km} ; A_{B h}=$ Área da bacia $\mathrm{em} \mathrm{km}^{2}$.

$$
D_{d}=\frac{L_{t}}{A_{B h}}
$$

Gradiente dos canais $\left(G_{c}\right)$ : indica a declividade dos cursos d'água (CHRISTOFOLETTI, 1980). Foi calculado através da equação de Horton (1945 apud SANTOS e MORAIS, 2012, p. 620) e (LANA, ALVES e CASTRO, 2001, p. 5). Onde: $A M^{x}=$ Altitude máxima em metros e $C_{c p}=$ Comprimento do canal principal em metros.

$$
G_{c}=\frac{A M^{x}}{C_{c p}}
$$




\section{Resultados e Discussões}

Os dados revelam que, com área de $5.762,08 \mathrm{~km}^{2}$, perímetro de $918 \mathrm{~km}$ e canal principal com 231,86 Km de extensão, a bacia hidrográfica do rio Cabaçal apresenta perfil longitudinal disposto no sentido noroeste (a montante) sudoeste (a jusante) e concentra uma rede de drenagem de 12.744,38 Km de canais (Tabela I).

Tabela I - Dados e Parâmetros Morfométricos da

Bacia Hidrográfica do Rio Cabaçal-MT

\begin{tabular}{lr}
\hline Dados e Parâmetros Morfométricos & Resultados \\
\hline Área da bacia $\left(\mathrm{Km}^{2}\right)$ & $5.762,08 \mathrm{Km}^{2}$ \\
Perímetro $(\mathrm{km})$ & $918,97 \mathrm{Km}$ \\
Comprimento do canal Principal & $231,86 \mathrm{Km}$ \\
Comprimento total de canais & $12.744,38 \mathrm{Km}$ \\
Amplitude Altimétrica (m) & 605 \\
Altitude Média (m) & 409,5 \\
Declividade média (\%) & $13,8 \%$ \\
Hierarquia Fluvial (Ordem) & $8^{\mathrm{a}}$ Ordem \\
Índice Compacidade & 3,39 \\
Índice Circularidade & 0,08 \\
Fator Forma & 0,24 \\
Razão de Relevo & 0,003 \\
Densidade de Rios $\left(\mathrm{Canais} / \mathrm{Km}^{2}\right)$ & 5,8 \\
Densidade de drenagem $\left(\mathrm{Km} / \mathrm{Km}^{2}\right)$ & 2,2 \\
Gradiente de canais $(\%)$ & $3,07 \%$ \\
\hline
\end{tabular}

O padrão da drenagem constatado é do tipo dentrítico (Figura 2), para Christofoletti (1980, p. 103) esse padrão também é chamado de arborescente, por se assemelhar a configuração de uma arvore, sendo um padrão que se desenvolve sobre estruturas rochosas de resistência uniforme ou em estruturas sedimentares horizontalmente distribuídas. Definição está compatível com as estruturas geológicas da bacia, Mirandola-Avelino (2006) que afirma que a bacia encontra-se sobre estruturas transicionais do Complexo Xingu, Grupo Alto Paraguai e Grupo Parecis.

Diretamente ligado ao tipo de substrato geológico o sistema de drenagem da bacia foi classificado como de $8^{\circ}$ ordem, o que lhe confere um eficiente sistema de drenagem de acordo com os critérios de Strahler (1957) que estabelece que "quanto mais ramificada a rede, mais eficiente será o sistema de drenagem" (Figura 2). 


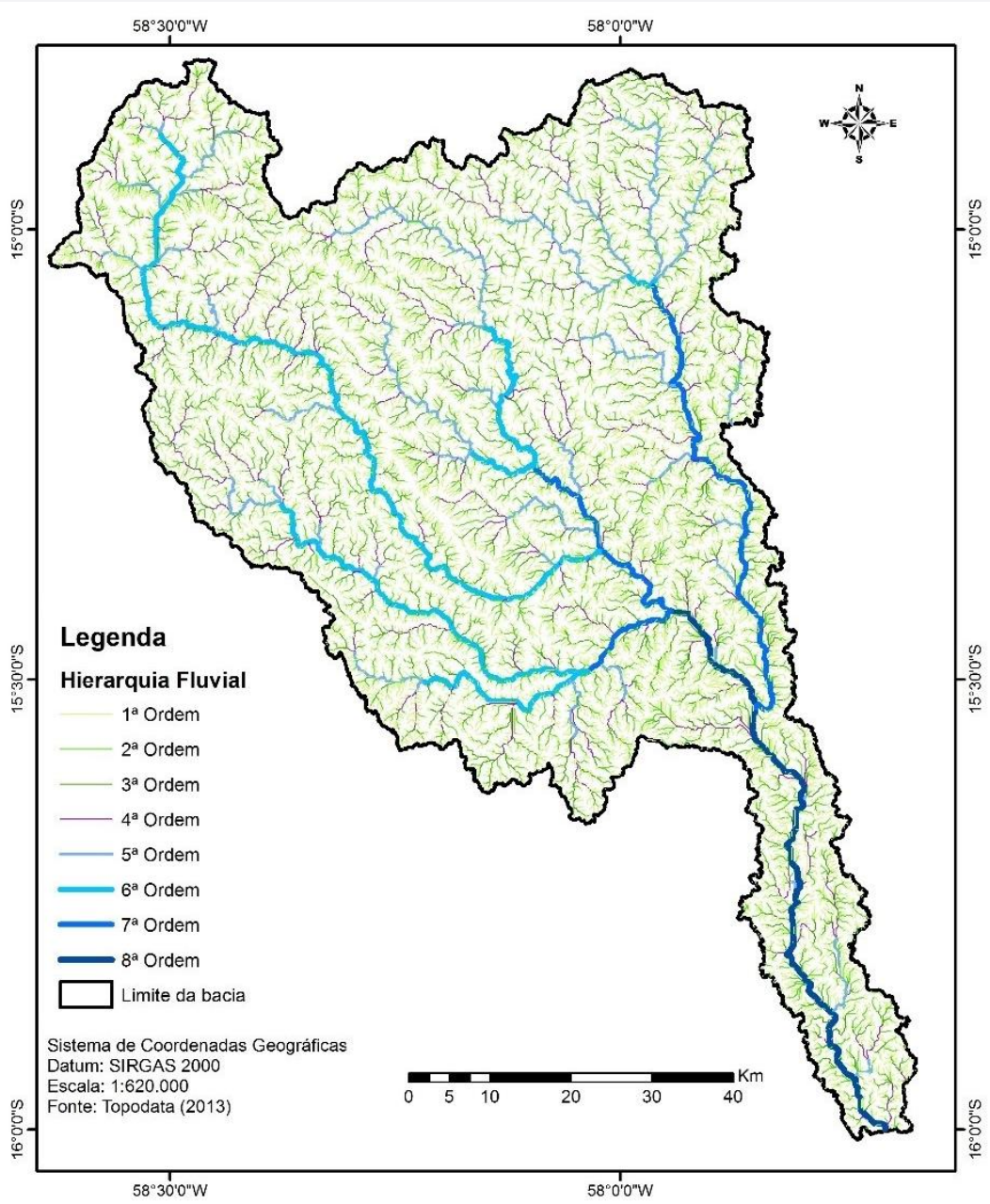

Figura 2-Mapa da Rede de Drenagem Ordenada de acordo com Strahler (1957)

Outro fator que evidencia o potencial de drenagem da bacia é o elevado índice de densidade dos rios, na ordem de 5,8 canais por $\mathrm{km}^{2}$, sendo este um importante indicador de capacidade de escoamento das aguas superficiais, uma vez que "bacias com alta densidade hidrográfica, pode-se inferir uma maior capacidade de gerar canais, independentemente de suas extensões" (VEIGA SANTOS, et al., 2013, p. 131).

Observando os critérios de classificação da densidade da drenagem de Beltrame (1994) apud Santos e Targa, et al, (2012, p. 202) que fixa os valores de até 0,5 como baixa densidade, de 0,5 a 2,00 média, 2,01 a 3,50 alta, e valores superiores a 3,50 como densidade de drenagem muito alta, constatamos que com 2,2 $\mathrm{km}$ de drenagem por $\mathrm{km}^{2}$. Assim, a bacia apresenta alta capacidade de drenagem, reforçando os parâmetros obtidos no ordenamento e densidade dos canais. 
O valor obtido para o parâmetro de gradiente dos canais foi de 3,07\% de declividade (Tabela I), "este parâmetro tem a finalidade de encontrar a declividade média do canal analisado, podendo ser expressa em porcentagem ou em grau, onde $100 \%$ correspondem a $45^{\circ}$ de inclinação" (SANTOS e MORAIS, 2012, p. 626). O gradiente de 3,7\% evidencia que a bacia possui canais com moderada capacidade de escoamento (relacionada à declividade), considerando por tanto a totalidade da bacia, contudo conforme variação altimétrica e cotas acentuadas de declividade (Figura 3 e 4) observadas na porção noroeste da bacia, quando se analisa setores específicos, pode-se obter percentuais de gradiente (\% declividade média) mais elevados.

Indo de encontro com os dados de densidade (rios e drenagem), o índice de compacidade de 3,39, torna evidente que a bacia não é propensa a grandes enchentes, por se distanciar do valor de 1,00. Considerando os valores atribuídos a suscetibilidade a cheias de Costa e Lança (2011) valores entre 1,00 e 1,25 apresentam alta propensão a grandes enchentes e de 1,25 a 1,50 media propensão e valores superiores a 1,50 representam bacias não propensas a grandes eventos de enchentes.

O Índice de circularidade da bacia foi de 0,08, fato que corrobora com os dados de densidade, confirmando a boa capacidade de escoamento, por se aproximar do formato alongado (índice este reforçado inda pelo coeficiente de compacidade de 3,39). Alves e Castro (2003 apud VEIGA e SANTOS, et al., 2013, p. 131), destacam que: "esse parâmetro indica uma bacia mais alongada (com índice abaixo de 0,51 ) favorece o escoamento, e se estiver acima de 0,51, a bacia tem forma geométrica mais circular com escoamento reduzido e alta probabilidade de cheias".

O fator de forma de 0,24 obtido nas análises reforça a indicação de que a bacia é pouco propensa a enchentes, pois o índice obtido se distancia de um $(1,00)$, "uma bacia com um fator de forma baixo é menos sujeita a enchentes que outra de mesmo tamanho, porém com fator de forma maior". (FILHO, MACIEL, et al., 2013, p. 42). Esta escala pode ainda ser classificada na seguinte ordem: valores inferiores a 0,50 apresentam baixa propensão a enchentes, de 0,50 a 0,75 média propensão e de 0,75 a 1,00 altamente propenso a grandes enchentes.

O levantamento de dados altimétricos demostram que a bacia apresenta altitude média de 383,5 metros, com máxima de 712 ao norte e mínima de 107 metros ao sul, conferindo-lhe amplitude altimétrica de $13,8 \%$ de declividade media. As áreas contidas no alto curso da bacia apresentam as maiores cotas altimétricas e consequentemente declividade media elevada. Nestas áreas a altitude oscila entre 383 e 712 metros de elevação e declividade entre 0 e 70\%, com relevo classificado de plano a escarpado, com predominância de declividades superiores a $5 \%$. A porção leste do alto curso da bacia apresenta relação de altitude e declividade contrastante com as demais áreas de cabeceiras, pois prevalece altitudes inferiores a 
561 metros de altitude e declividade inferiores a 15\%, com relevo classificados entre fortemente ondulado a plano (Figuras 3 e 4 ).

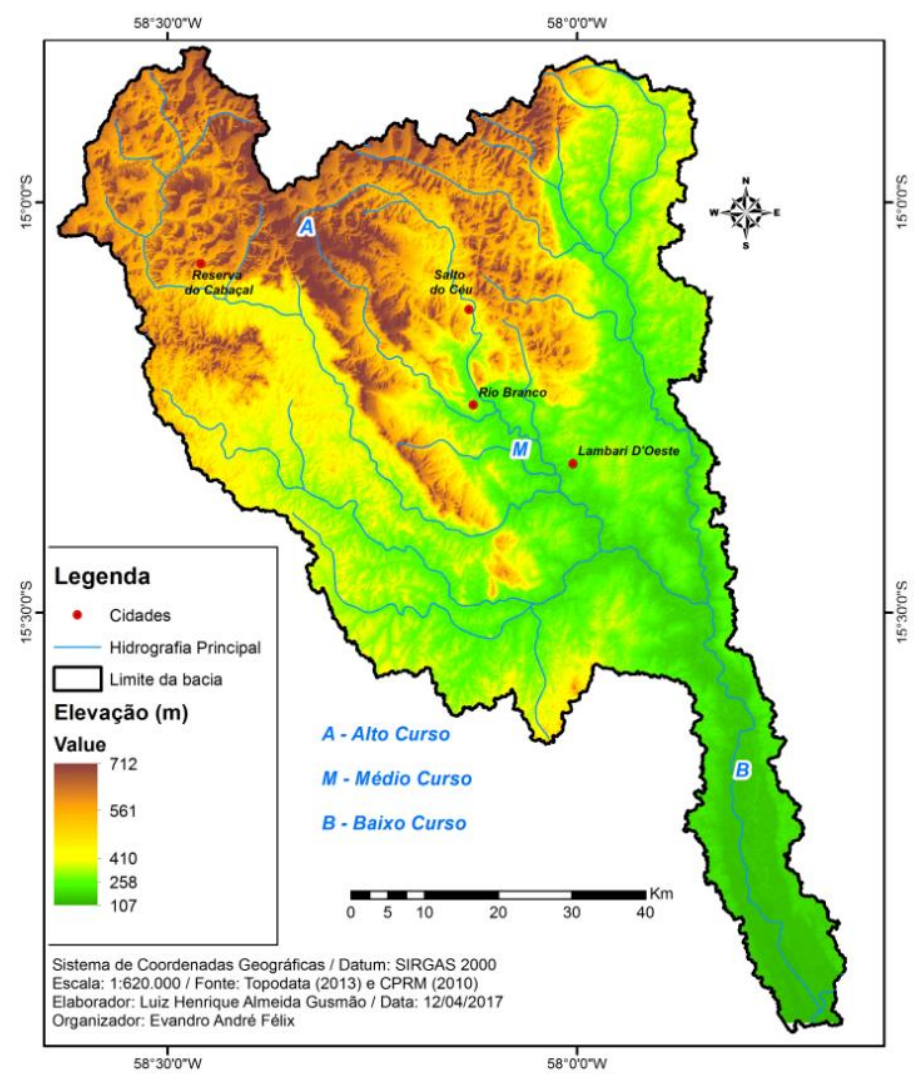

Figura 3- Mapa de elevação da bacia

Hidrográfica do Rio Cabaçal - MT

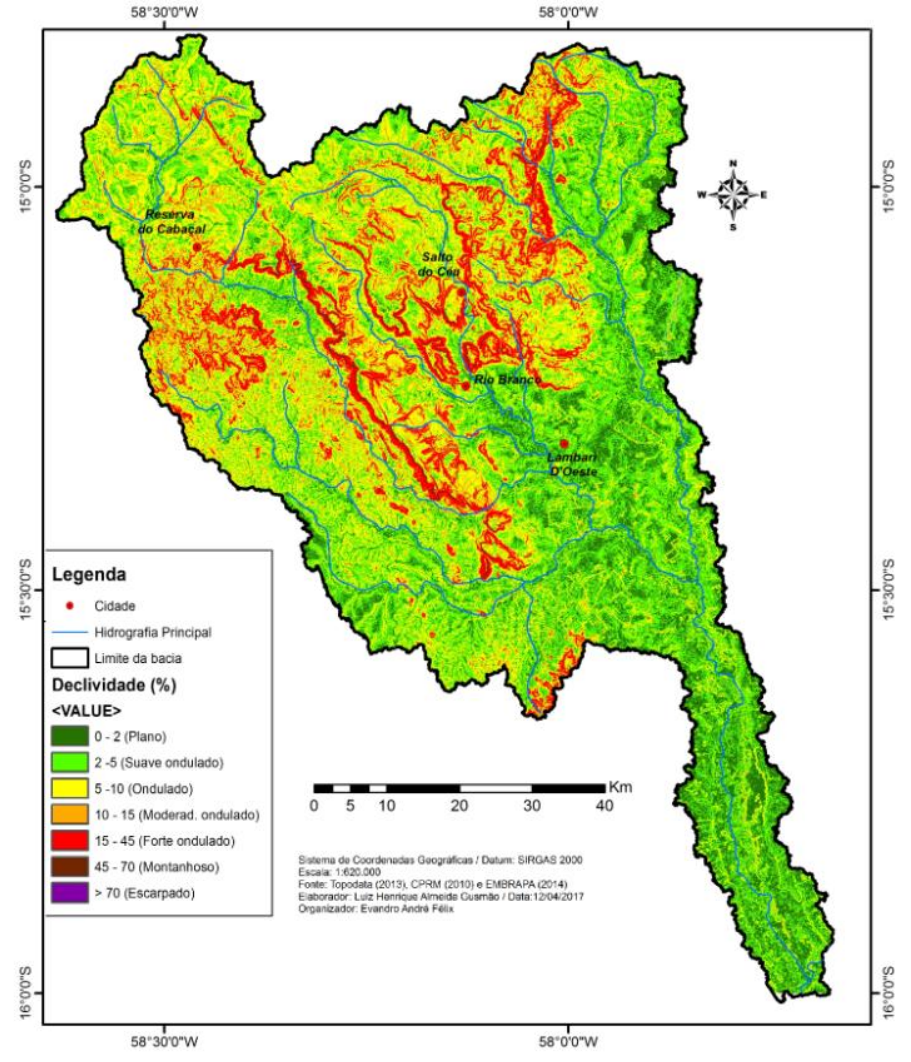

Figura 4-Mapa de Declividade da Bacia Hidrográfica do Rio Cabaçal-MT

O médio e baixo curso da bacia apresenta certa homogeneidade, tanto nas cotas altimétricas quanto nos percentuais de declividade, sendo áreas que oscilam entre 581 a 107 metros de altitude, com predomínio de cotas abaixo de 258 metros e declives abaixo de $10 \%$, caracterizando relevos planos, suave ondulado e ondulado.

A correlação entre amplitude altimétrica e a maior área observada da bacia data através do parâmetro relação do relevo foi de 0,003. Considerando a classificação de Piedade (1980) apud Pinto (2015, p. 29), que estabelece que, "entre 0,0 a 0,10 tem-se baixa relação do relevo, entre 0,11 a 0,30 média relação de relevo e de 0,31 a 0,60 alta relação do relevo", pode-se contatar que a bacia hidrográfica apresenta baixa relação do relvo, lhe conferindo um escoamento com velocidade variando de baixa a moderada. 
De acordo com Mirandola-Avelino (2006) o clima da bacia e do tipo AW (KOPPEN), com verão de chuvas intensas (100 a $370 \mathrm{~mm} / \mathrm{mês})$, e inverno seco $(10$ a $80 \mathrm{~mm} / \mathrm{m})$, e variação anual entre 1000 a $1500 \mathrm{~mm}$, o regime hidrológico portanto apresenta uma intermitência pluviométrica que associada a intensa distribuição da rede de drenagem (densidade dos rios e canais), picos de cheias (intensidade da vazão e escoamento superficial) e variação altimétrica provoca e acelera processos erosivos observados principalmente nas cabeceiras onde situam-se as cotas altimétricas de até 712 metros de altitude.

A relação da densidade da drenagem com o relevo associadas tipo de solo, ainda reforçam suscetibilidade da bacia a erosão superficial. Segundo Carvalho (2015, p. 31) os solos presentes na bacia, são classificados como extremamente a moderadamente susceptíveis à erosão hídrica, em decorrência das suas características físicas químicas e mineralógicas.

Carvalho (2015), Lorenzon, Paiva, et al (2014, p. 422-423) afirmam que a "conservação das Áreas de Preservação Permanente das nascentes da Bacia Hidrográfica do Rio Cabaçal demonstrou que houve perdas da cobertura vegetal que comprometem a conservação desse tipo de corpo hídrico". Em estudo realizado nas cabeceiras do rio Cabaçal e Jauru, por Félix, Padilha, et al (2016), apontam que o aumento do uso agrícola da terra no período de 2003 a 2015 foi de 124,7\%, e a pecuária tem apresentado crescimento superior a $28 \%$ ao ano.

Portanto ao relacionarmos os parâmetros morfométricos associados ao tipo e uso do solo e condições ambientais atuais, constata-se que a bacia apresenta grande potencial erosivo. A relação tipo de solo, densidade dos rios e drenagem e as cotas altimétricas, determinam, portanto, o limiar e o potencial erosivo da bacia, que pode ser potencializado pela retirada da cobertura vegetal decorrente da expansão da agricultura e pecuária, que tem se dado de forma exponencial nos últimos anos.

Cardoso e Dias, et al (2006) destacam que a cobertura vegetal exerce função de interceptação e redistribuição das aguas pluviais, sua remoção pode desencadear processos erosivos sistêmicos que degradam o ambiente, expandindo dos pontos de ruptura (drenagens acentuadas e concentradas em áreas de declives) a áreas adjacentes. Deste modo a declividade e a cobertura vegetal são fatores primordiais a serem considerados, no manejo de bacia hidrográficas, pois influenciam diretamente na precipitação efetiva, escoamento superficial e fluxo de água no solo.

Observando os parâmetros de ordem, densidade (rios e drenagem), fator de forma e índice de compacidade e circularidade constata-se que a bacia uma vez exposta as condições de uso inapropriado ao tipo de solo pode tornar a bacia vulnerável a atuação de processos de degradação, pois estes parâmetros evidenciam a alta capacidade que a bacia tem de escoar as aguas superficiais, fato que reduz a probabilidade de inundação e aumenta a capacidade de erosão tendo em vista a exposição de grandes áreas 
ao potencial erosivo do escoamento superficial das aguas. Cabendo o ponto de equilíbrio ao gradiente de canais, amplitude altimétrica e relação do relevo que no todo apresentam índices relativamente baixos.

\section{Considerações Finais}

Considerando os resultados morfométricos, pode-se concluir que: a bacia hidrográfica do rio Cabaçal aponta para uma bacia de forma alongada, como aponta os índices de circularidade, coeficiente de compacidade e fator de forma, fato que indica forte controle estrutural da drenagem. Sua porção norte no alto curso onde predomina as maiores altitudes e índices de declividade apresenta formato retangular, seguido de um rápido estreitamento que se estende do médio curso no centro da bacia até o baixo curso na foz com o rio Paraguai.

Com densidade de drenagem de 2,2 km/ $\mathrm{km}^{2}$, e densidade dos rios de 5,8 canais por $\mathrm{km}^{2}$, podemos afirmar que a bacia é intensamente dissecada e perene, em função das caraterísticas do relevo e pluviosidade elevada, que determina o elevado índice de ramificação ( $8^{\circ}$ ordem).

Por fim, os parâmetros evidenciam uma rede de drenagem que favorece a circulação das águas superficiais e subsuperfíciais, o que reduz significativamente o tempo de retenção/permanência das águas nos canais fluviais e vertente em áreas susceptíveis a erosão. Indicando, portanto, que os mesmos fatores que a distanciam de riscos de inundação a aproximam da suscetibilidade a erosão/degradação devido a exposição do grande número de canais fluviais/drenagem a atividade antrópica associado a áreas com alto grau de fragilidade geológica.

\section{Bibliografia.}

CARDOSO, C. et al. CARACTERIZAÇÃO MORFOMÉTRICA DA BACIA HIDROGRÁFICA DO RIO DEBOSSAN, NOVA FRIBURGO, RJ. Árvore, Viçosa, v. 30, n. 2, p. 241-248, 2006. ISSN 1806-9088.

CARVALHO, J. M. Degradação dos solos por erosão hídrica, sob áreas de pastagem, na bacia hidrográfica do rio Cabaçal - região sudoeste do estado de Mato Grosso, Brasil. Universidade do Estado de Mato Grosso. Tangará da Serra, p. 54. 2015.

CASTRO, P.; LOPES, J.D.S, J. D. S. Recuperação e conservação de nascentes. Viçosa, MG.

CHRISTOFOLETTI, A. Geomorfologia. 2º. ed. São Paulo: Blucher, 1980. ISBN 9788521201304.

COSTA, T. D.; LANÇA, HIDROLOGIA DE SUPERFICIE. FARO: INSTITUTO SUPERIOR DE ENGENHARIA, 2011.

FÉLIX, E. et al. Análise da cobertura vegetal e evolução do uso da terra nas cabeceiras dos rios Jauru e. Anais $6^{\circ}$ Simpósio de Geotecnologias no Pantanal, Cuiabá, 22-26 Outubro 2016. 180 -190. 
FILHO, G. M. M. et al. AVALIAÇÃO DE CARACTERÍSTICAS MORFOMÉTRICAS DA BACIA HIDROGRÁFICA DO RIO FORMOSO - TO. REVISTA DE CIÊNCIAS AMBIENTAIS, Canoas, v. 7, n. 1, p. 37-48, Julho 2013. ISSN 1981-8858.

FRANÇA, J. M. B. D. et al. Morfometria e uso e ocupação da bacia hidrográfica do Carão, Estado do Ceará, Brasil. Anais XVI Simpósio Brasileiro de Sensoriamento Remoto - SBSR, Foz do Iguaçu, 13 a 18 Abril 2013. 81388145.

GARCEZ, L. N.; ALVAREZ, , G. A. Hidrologia. São Paulo: Editora Edgar Blücher, 1988.

GUERRA, ; GUERRA, A. J.. Dicionário Geológico - Geomorfológico. 3. ed. Rio de Janeiro : Bertrand, 2003.

LANA, C. E.; ALVES, M. D. P.; CASTRO, P. D. T. A. Análise morfométrica da bacia do Rio do Tanque, MG Brasil. REM - International Engineering Journal, v. 54, n. 2, p. 121-126, Junho 2001. ISSN 0370-4467.

LORENZON, T. et al. Geotecnologias aplicadas à análise do estado de conservação das APPs das nascentes da bacia hidrográfica do rio Cabaçal, Mato Grosso - Brasil. Anais $5^{\circ}$ Simpósio de Geotecnologias no Pantanal, Campo Grande, MS, 22 a 26 Nvembro 2014. 415-425.

MACHADO , A. S. et al. Análise morfométrica de bacias hidrográficas como suporte a definição e elaboração de indicadores para a gestão ambiental a partir do uso de geotecnologias. Anais XV Simpósio Brasileiro de Sensoriamento Remoto - SBSR, Curitiba, 5 Maio 2011. 1441-1448.

MIRANDOLA-AVELINO, P. H. nálise Geo-Ambiental Multitemporal para fins de Planejamento Ambiental: Um exemplo aplicado à Bacia Hidrográfica do Rio Cabaçal, Mato Grosso - Brasil. Universidade Federal do Rio de Janeiro. Rio de Janeiro, p. 317. 2006.

NETO, R. M. A ABORDAGEM SISTÊMICA E OS ESTUDOS GEOMORFOLÓGICOS: ALGUMAS INTERPRETAÇÕES E POSSIBILIDADES DE APLICAÇÃO. Revista do Departamento de Geociências UEL, Londrina, v. 17, n. 2, p. 67-87, jul./dez. 2008. ISSN 0102-3888.

PINTO, V.. CARACTERIZAÇÃO MORFOMÉTRICA E CAPACIDADE DE USO DA TERRA DA BACIA HIDROGRÁFICA DO RIO SARARÉ, SUDOESTE DO ESTADO DE MATO GROSSO. UNEMAT. Cáceres, p. 87. 2015.

SALLES, M. M. O USO DO SIG NA ANÁLISE MORFOMÉTRICA DA BACIA HIDROGRÁFICA DO RIO SÃO JOÃO - MG. Universidade Federal de Minas Gerais. Belo Horizonte, p. 39. 2010. (528.8).

SANTOS, A. M. D. et al. Análise morfométrica das sub-bacias hidrográficas Perdizes e Fojo no município de Campos do Jordão, SP, Brasil. Revista Ambiente \& Água, v. 7, n.3, 2012, v. 7, n. 3, p. 95-211, Taubaté 2012. ISSN 1980-993X.

SANTOS, D. A. R. D.; MORAIS, F.. ANÁLISE MORFOMÉTRICA DA BACIA HIDROGRÁFICA DO RIO LAGO VERDE COMO SUBSÍDIO À COMPARTIMENTAÇÃO DO RELEVO DA REGIÃO DE LAGOA DA CONFUSÃO - TO. REVISTA GEONORTE, v. 3, n. 4, p. 617-629, Edição Especial 2012. ISSN 2237-1419.

SEHNEM, et al. ANÁLISE DA MORFOMETRIA DE BACIAS HIDROGRÁFICAS SUJEITAS A INUNDAÇÕES NA REGIÃO SUL DE SANTA CATARINA - BRASIL. XXI Simpósio Brasileiro de Recursos Hídricos, Brasília, 22-27 Novenbro 2015. 1-8.

SOUSA, J. D. S.; ARRAES, C. ; COSTA, A. L. D. Caracterização morfométrica de sub-bacias hidrográficas na calha do rio Solimões /Amazonas. Anais do SICASA e ANPPAS Amazônia, 22 Novembro 2016. 1-10.

SOUZA, C. A. D. et al. SEDIMENTAÇÃO NO RIO PARAGUAI E NO BAIXO CURSO DOS TRIBUTÁRIOS SEPOTUBA, CABAÇAL E JAURU, MATO GROSSO, BRASIL. Egal14. Disponivel em: <http://observatoriogeograficoamericalatina.org.mx/egal14/Procesosambientales/Hidrologia/02.pdf.>. Acesso em: 05 Dezembro 2016.

TONELLO, K. et al. MORFOMETRIA DA BACIA HIDROGRÁFICA DA CACHOEIRA DAS POMBAS, GUANHÃES - MG. R. Árvore, Viçosa, v. 30, n. 5, p. 849-857, 2006. ISSN 1806-9088.

VEIGA, A. M. et al. CARACTERIZAÇÃO HIDROMORFOLÓGICA DA BACIA DO RIO MEIA PONTE. CAMINHOS DE GEOGRAFIA, Uberlândia, v. 14, n. 46, p. 126 - 138, Junho 2013. ISSN 1678-6343. 